DOI 10.17816/transsyst201843s1156-164

(C) Y. Yang, J. Deng, L. Tong, X. Li, Q. Peng, W. Zhang

CRRC Zhuzhou Locomotive CO., LTD

(Zhuzhou, China)

\title{
STUDY ON THE OPTIMIZATION OF LINEAR INDUCTION MOTOR TRACTION SYSTEM FOR FAST-SPEED MAGLEV TRAIN
}

Background: The short stator linear induction motor (LIM) is normally used in mediumlow speed maglev train.

The restriction by mounting space on bogie and motor input voltage from the third power supply rail lead that the maximum speed of medium-low speed maglev train can reach no more than $120 \mathrm{~km} / \mathrm{h}$.

Aim: In this paper, by means of the LIM design optimization, improvement of the LIM force characteristic in high speed range, the maximum speed of medium-low speed maglev train can reach $160 \mathrm{~km} / \mathrm{h}$.

Methods: After comparing the LIM theoretical calculation and actual test data, it shows that the new designed LIM is effective.

Conclusion: Afterwards, by installing the new designed LIMs, the traditional medium-low speed maglev train becomes a fast-speed maglev train, and it has a bright future in transportation applications.

Keywords: linear induction motor, maglev train, medium-low speed, fast-speed, suspension bogie, traction system, F-shaped track, Changsha maglev express.

\section{INTRODUCTION}

Till now, three maglev research and development groups in China have respectively built three $1.5 \sim 1.7 \mathrm{~km}$ long medium-low speed maglev engineering test line in Zhuzhou, ShanghaiandTangshan. All these three test trains on the three test lines use linear induction motors (LIM) with VVVF converter and control system. Due to the restriction of mounting space on the suspension bogie and motor input voltage (DC $1500 \mathrm{~V}$ converted for 5 series connection motors), the maglev train can reach the highest limit speed about $100 \mathrm{~km} / \mathrm{h}$.

As China's first, the world's longest commercial short stator medium-low speed maglev line - Changsha maglev express was put into application in 2016, the medium-low speed maglev train with advantages of green, quiet and comfortable, strong climbing ability, small turning radius and low construction cost, reflects the strong adaptability to the environment and higher economy in city rail transportation 
applications [1]. The Changsha maglev express as showed in Fig. 1 uses short stator linear induction motor (LIM, the structure is indicated in Fig. 2) to drive, since LIM with simple structure and no intermediate transmission device that can directly generate linear movement thrust, has been widely used in the fields of industry applications such as transportation, maglev train, subway / light rail train, piling machine, pumping device, electric vehicle door [2, 3]. Maglev train with no traditional wheel and rail, and the state of train operation, such as traction and braking, positive and reverse operation, is completely realized by linear motor frequency converter system. The main circuit of the traction system of maglev train consists of traction inverter, linear motor and corresponding control and detection circuit [4]. Due to the special structure of the maglev vehicle, the linear motor in the medium-low speed maglev train with the short length of air gap, terrible electromagnetic load, weight index of strict restrictions, leads to some difficulties for the design and manufacture. Generally, in order to achieve matched traction / braking characteristics, the speed of the maglev train resistance characteristics is calculated firstly, then, the related technical parameters and the design of single motor and traction inverter for obtaining the required traction power and traction characteristics are specified.

Many researches of the design and performance analysis of LIM have been done around the word, and in those researches also a lot of simulations and measurements are carried out $[5,6]$. With some of those studies, the formation of improvement design of LIM have provided experience for faster speed applications.

For some application situations of urban or suburban, higher maximum speed maglev trains are expected, for example airport or satellite city connection

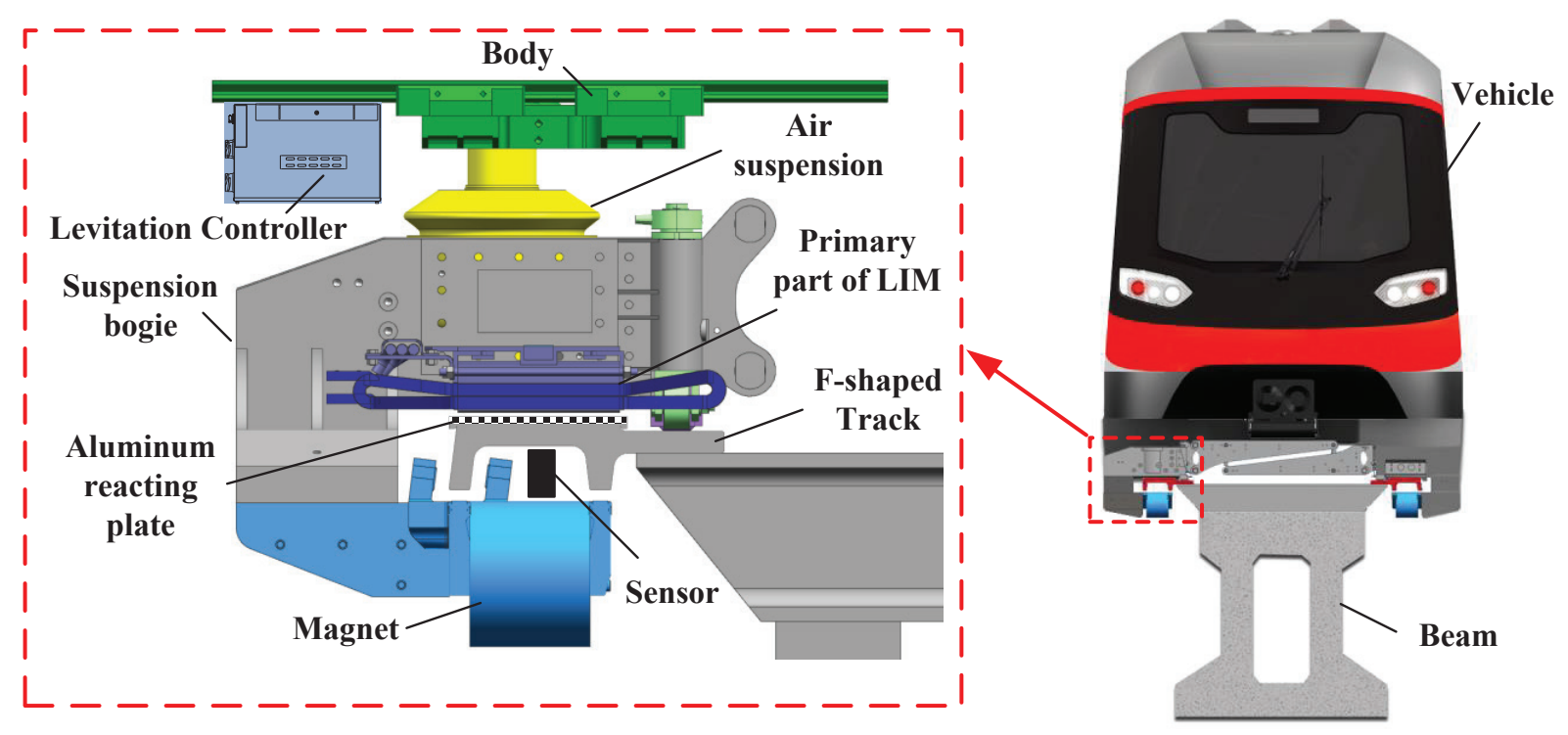

Fig. 1. The levitation and traction structure of medium-lowspeed maglev train 


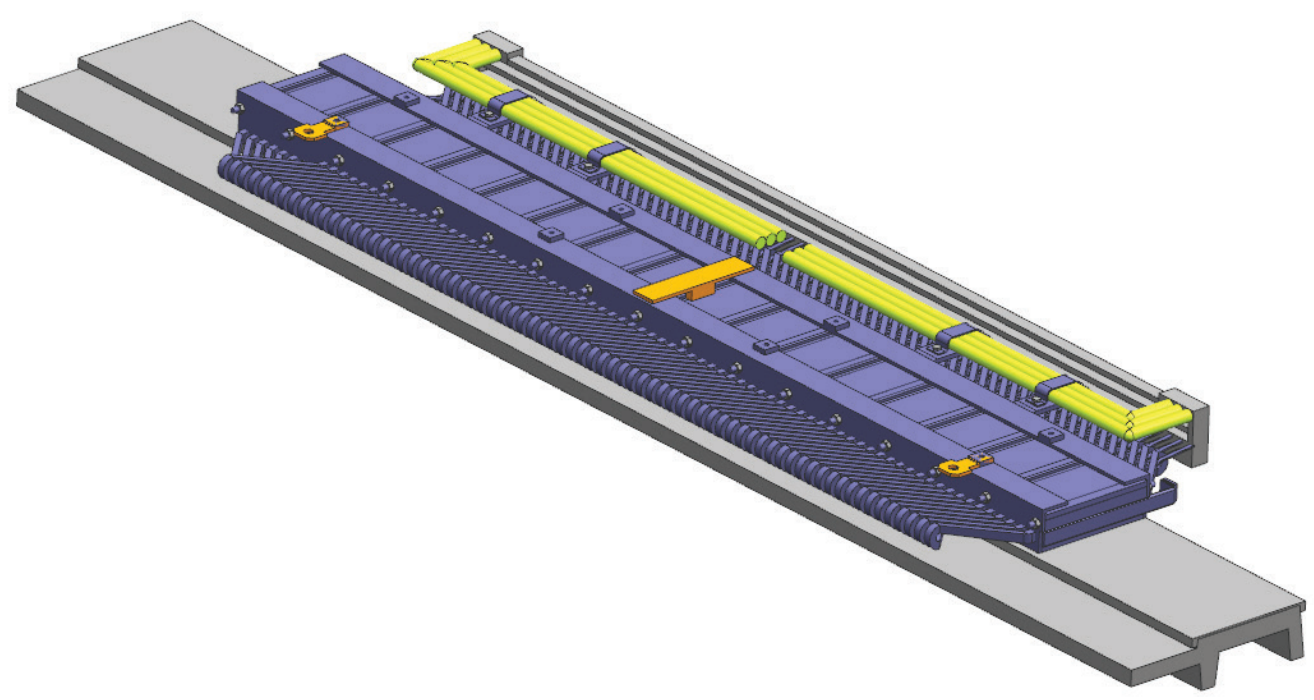

Fig. 2. The primary and secondary parts of a LIM

to downtown. Therefore, a new LIM is specially proposed and realized to meet the higher speed requirement. Through optimization of the traction system including VVVF converter, the highest speed could reachup to $160 \mathrm{~km} / \mathrm{h}$ according to theoretical calculation and actual comparison.

\section{DESIGN OF THE NEW LIM FAST-SPEED MAGLEV TRAIN IN COMPARISON WITH THE ORIGINAL LIM FOR CHANGSHA MAGLEV EXPRESS}

Tab.1 shows the main parameter and dimension of the LIM which is utilized in $160 \mathrm{~km} / \mathrm{h}$ fast-speed maglev train and the LIM which is used in Changsha maglev express. The whole speed rang force calculation showed that with the new LIM the train has the ability to run up to $160 \mathrm{~km} / \mathrm{h}$.

Table 1. Design data and performance of the new LIM for Fast-speed Maglev Train and the original LIM for Changsha maglev express

\begin{tabular}{|c|c|c|c|c|}
\hline \multirow{2}{*}{ Items } & Design Data & Sign & $\begin{array}{c}\text { LIM of Fast-speed } \\
\text { Maglev Train }\end{array}$ & $\begin{array}{c}\text { LIM of Changsha } \\
\text { Maglev Express }\end{array}$ \\
\hline \multirow{4}{*}{$\begin{array}{l}\text { Perfor- } \\
\text { mance }\end{array}$} & Max.linevoltage (RMS) & $\mathrm{V}$ & $220 \mathrm{~V}$ & $220 \mathrm{~V}$ \\
\cline { 2 - 5 } & Max.primarycurrent & $\mathrm{I}_{1}$ & $450 \mathrm{~A}$ & $340 \mathrm{~A}$ \\
\cline { 2 - 5 } & Capacity & $\mathrm{S}$ & $170 \mathrm{kVA}$ & $130 \mathrm{kVA}$ \\
\cline { 2 - 5 } & Max.outputpower & $\mathrm{P}_{\mathrm{m}}$ & $48 \mathrm{~kW}$ & $36 \mathrm{~kW}$ \\
\cline { 2 - 5 } & Max.thrust & $\mathrm{F}_{\mathrm{m}}$ & $2800 \mathrm{~N}$ & $3100 \mathrm{~N}$ \\
\cline { 2 - 5 } & Max. speed & $\mathrm{v}_{m}$ & $160 \mathrm{~km} / \mathrm{h}$ & $100 \mathrm{~km} / \mathrm{h}$ \\
\hline
\end{tabular}




\begin{tabular}{|c|c|c|c|c|}
\hline \multirow{4}{*}{ Items } & Design Data & Sign & $\begin{array}{c}\text { LIM of Fast-speed } \\
\text { Maglev Train }\end{array}$ & $\begin{array}{c}\text { LIM of Changsha } \\
\text { Maglev Express }\end{array}$ \\
\hline \multirow{4}{*}{$\begin{array}{l}\text { Stator } \\
\text { Parameter }\end{array}$} & Numberofphases & $\mathrm{m}$ & 3 & 3 \\
\cline { 2 - 5 } & Numberofpoles & $2 \mathrm{p}$ & 8 & 8 \\
\cline { 2 - 6 } & Polepitch & $\mathrm{t}$ & $225 \mathrm{~mm}$ & $202.5 \mathrm{~mm}$ \\
\cline { 2 - 6 } & Lengthofstator & $\mathrm{L}$ & $2020 \mathrm{~mm}$ & $1820 \mathrm{~mm}$ \\
\cline { 2 - 6 } & Thicknessofironcore & $\mathrm{H}$ & $220 \mathrm{~mm}$ & $220 \mathrm{~mm}$ \\
\cline { 2 - 6 } & Heightofironcore & $\mathrm{d}_{\mathrm{a}}$ & $58 \mathrm{~mm}$ & $58 \mathrm{~mm}$ \\
\cline { 2 - 6 } & Overalldimensions & & $2020 \times 600 \times 110 \mathrm{~mm}$ & $1820 \times 580 \times 101 \mathrm{~mm}$ \\
\cline { 2 - 6 } & Numberofstatorslots & & 80 & 80 \\
\cline { 2 - 6 } & Windingconstruction & & doublelayerlapwinding & doublelayerlapwinding \\
\cline { 2 - 5 } & Wirematerials & & $\begin{array}{c}\text { silk- } \\
\text { coveredaluminiumwire }\end{array}$ & $\begin{array}{c}\text { silk- } \\
\text { coveredaluminiumwire }\end{array}$ \\
\cline { 2 - 5 } & Coolingmethod & & Naturalwindcooling & Naturalwindcooling \\
\hline
\end{tabular}

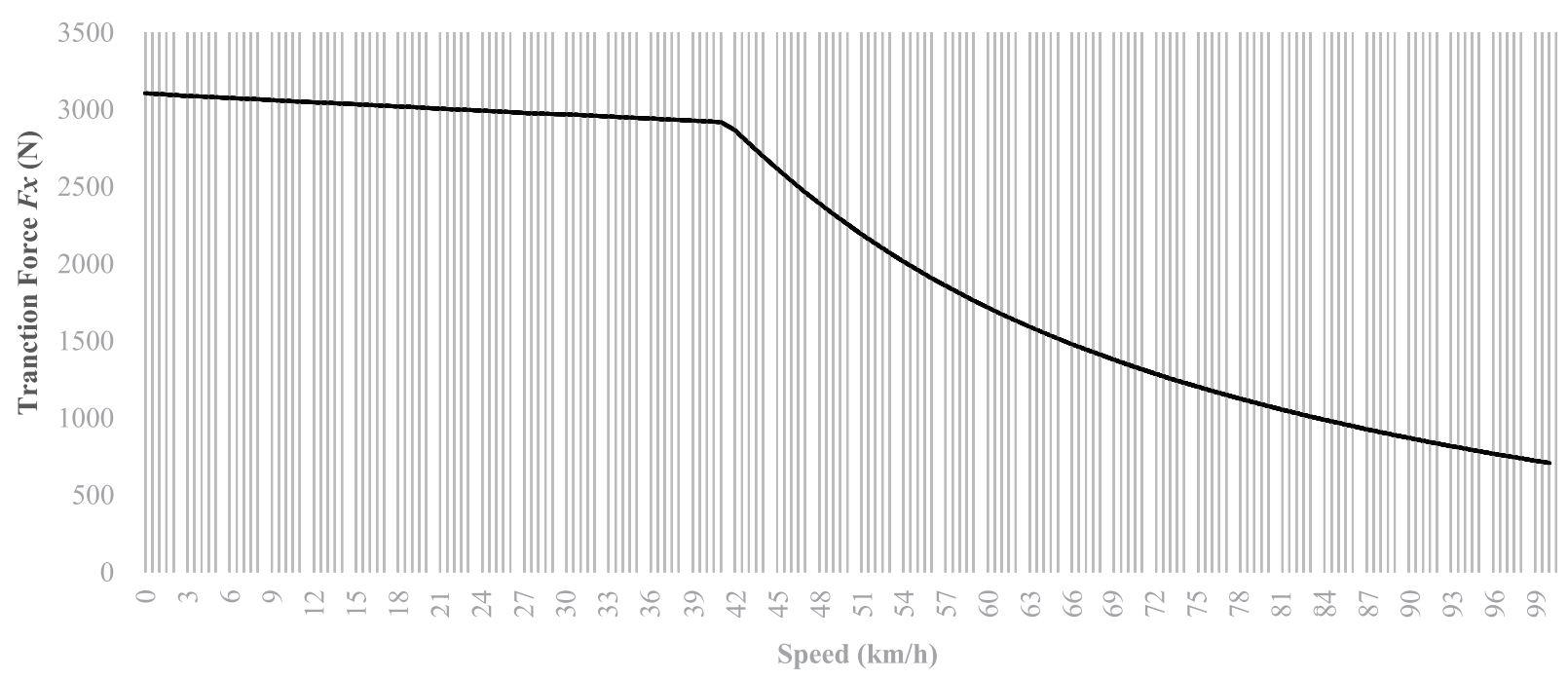

Fig. 3. Traction characteristic curve of the original LIM for Changsha maglev express (calculation with constant slip frequency $13.7 \mathrm{~Hz}$ )

As can be seen from Fig. 5, 6 and Tab. 2, the new LIM has better performance of equivalent stress and deformation than the original LIM.

\section{PRODUCTION AND INSTALLATION OF THE LIMS}

Since the new LIM is only $200 \mathrm{~mm}$ longer than the original LIM, the suspension bogie size of Fast-speed maglev train is unchangeable with respect to Changsha maglev express. With consideration of the support wheel and skids, some incidental modifications of the new LIM has been carried out (Fig. 7, 8). 


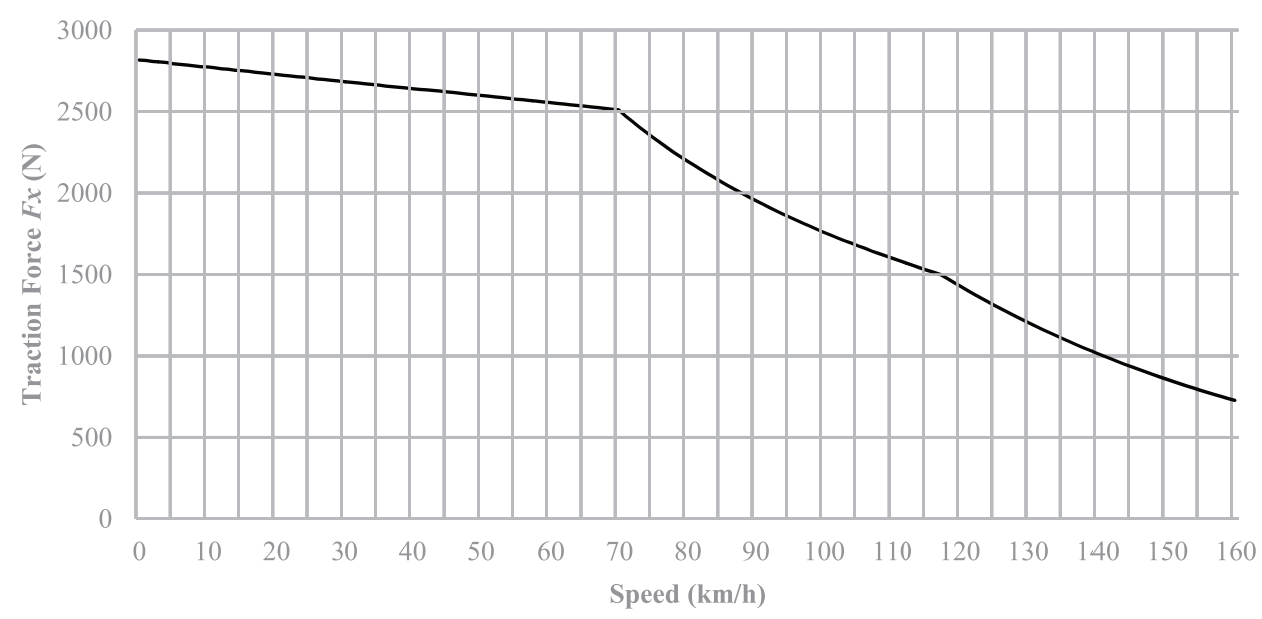

Fig. 4. Traction characteristic curve of the new LIM for Fast-speed maglev train (calculation with constant slip frequency $15 \mathrm{~Hz}$ )

\section{AC: Static Structural}

Equivalent Stress 2

Type: Equivalent (von-Mises) Stress

Unit: MPa

Time: 1

2017/8/10 8:36

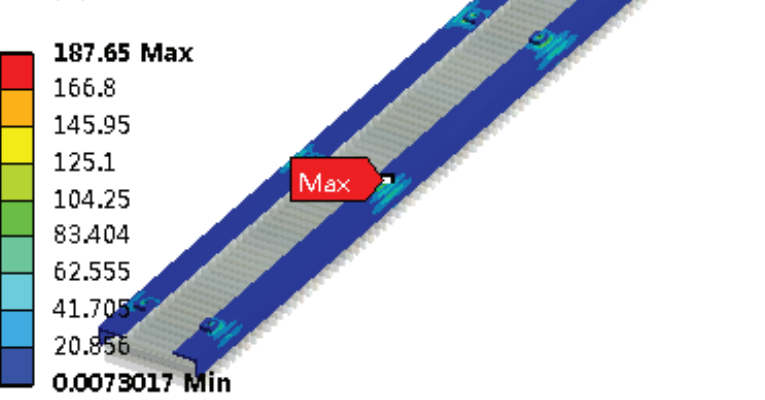

\section{AC: Static Structural}

Total Deformation 2

Type: Total Deformation

Unit: $\mathrm{mm}$

Time: 1

$2017 / 8 / 108: 42$

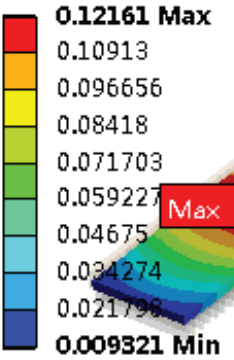

Fig. 5. Equivalent stress and deformation calculations of the original LIM for Changsha maglev express (impact acceleration value $15 \mathrm{~g}$ )

AA: JX-130 冲击 $15 \mathrm{~g}$

Equivalent Stress 2

Type: Equivalent (von-Mises) Stress

Unit: MPa

Time: 1

2017/8/9 20:53

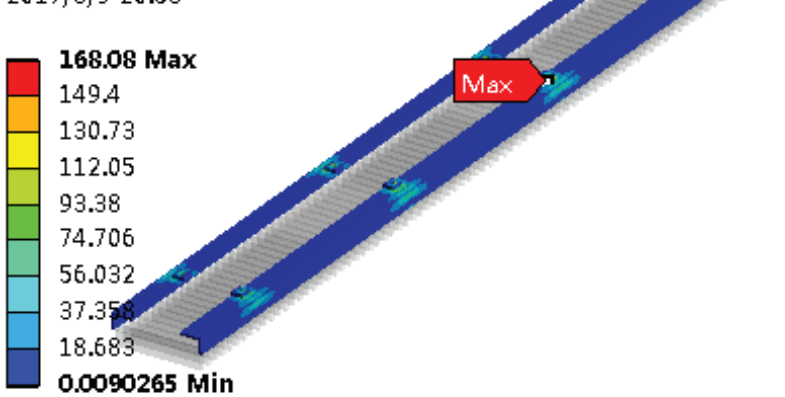

\section{AA: JX-130 冲击 $15 g$}

Total Deformation 2

Type: Total Deformation

Unit: $\mathrm{mm}$

Time: 1

2017/8/9 20:54

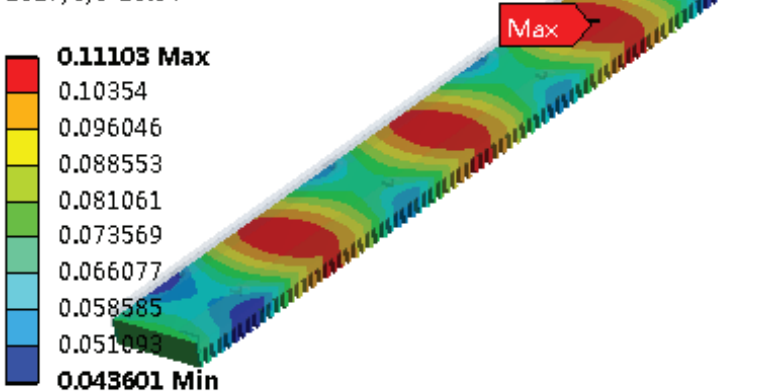

Fig. 6. Equivalent stress and deformation calculations of the new LIM for Fast-speed Maglev Train (impact acceleration value $15 \mathrm{~g}$ ) 
Table 2. The Statistical results of equivalent stress and deformation

\begin{tabular}{|l|c|c|c|}
\hline \multicolumn{1}{|c|}{ Model } & $\begin{array}{c}\text { Max. Equivalent } \\
\text { Stress (MPa) }\end{array}$ & $\begin{array}{c}\text { Max.Deformation } \\
\mathbf{( m m )}\end{array}$ & $\begin{array}{c}\text { Yield strength of } \\
\text { material (MPa) }\end{array}$ \\
\hline Theoriginal LIM & 188 & 0.122 & 235 \\
\hline Thenew LIM & 168 & 0.111 & 235 \\
\hline
\end{tabular}

Table 3. The Statistical results of traction and breaking

\begin{tabular}{|l|c|c|c|c|c|}
\hline \multirow{2}{*}{ Operation } & \multirow{2}{*}{ Items } & \multicolumn{2}{|c|}{ The new LIM } & \multicolumn{2}{c|}{ The original LIM } \\
\cline { 2 - 6 } & & Speed (km/h) & Thrust (N) & Speed (km/h) & Thrust (N) \\
\hline \multirow{3}{*}{ Traction } & Start-up & 0 & 2816 & 0 & 3105 \\
\cline { 2 - 6 } & Turning point & 70 & 2508 & 41 & 2920 \\
\cline { 2 - 6 } & Max. speed point & 160 & 726 & 100 & 708 \\
\hline \multirow{3}{*}{ Breaking } & Turning point end & 5 & 2820 & 5 & 3198 \\
\cline { 2 - 6 } & Turning point start & 135 & 2744 & 85 & 3198 \\
\cline { 2 - 6 } & Max. speed point & 160 & 1593 & 100 & 1938 \\
\hline
\end{tabular}

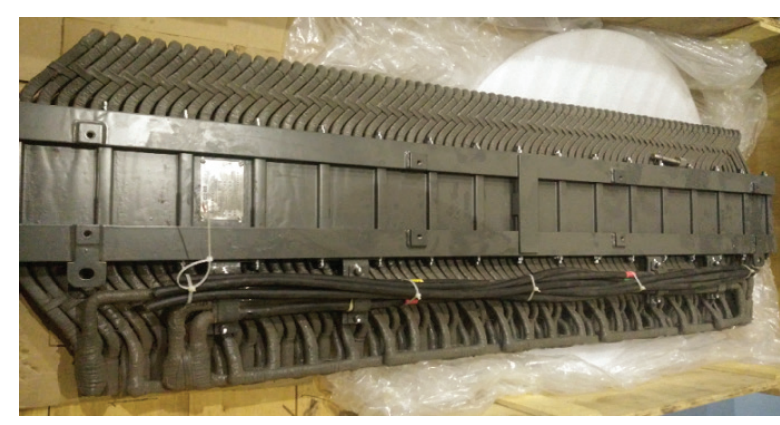

Fig. 7. The Original LIM (1820 mm)

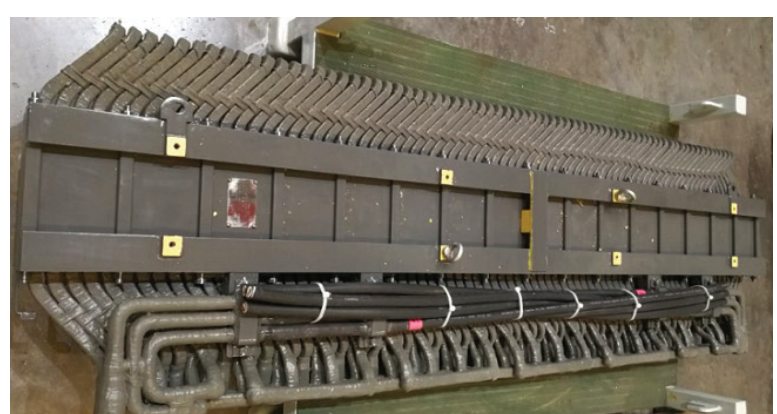

Fig. 8. The New designed LIM (2020 mm)

The support wheels and skids of the Fast-speed maglev train are similar with the ones of Changsha Maglev Express, which are located by the end of the suspension bogie close to the end of the LIM windings (Fig. 9, 10).

The Fast-speed maglev train with the new LIMs is composed of 3 marshalling vehicles, andeach vehicleowns5suspension bogies. The input DC $1500 \mathrm{~V}$ is converted to alternative voltage and equally distributed tofive series connection LIMs. The maximum voltage foreach LIM is about AC $220 \mathrm{~V}$. According to the propulsion calculation and whole-size model simulation with Finite Element Analysis (FEA), the maximum speed of the maglev train equipped with new LIMs is up to $160 \mathrm{~km} / \mathrm{h}$, and the remainder acceleration value is $0.15 \mathrm{~m} / \mathrm{s}^{2}$. 


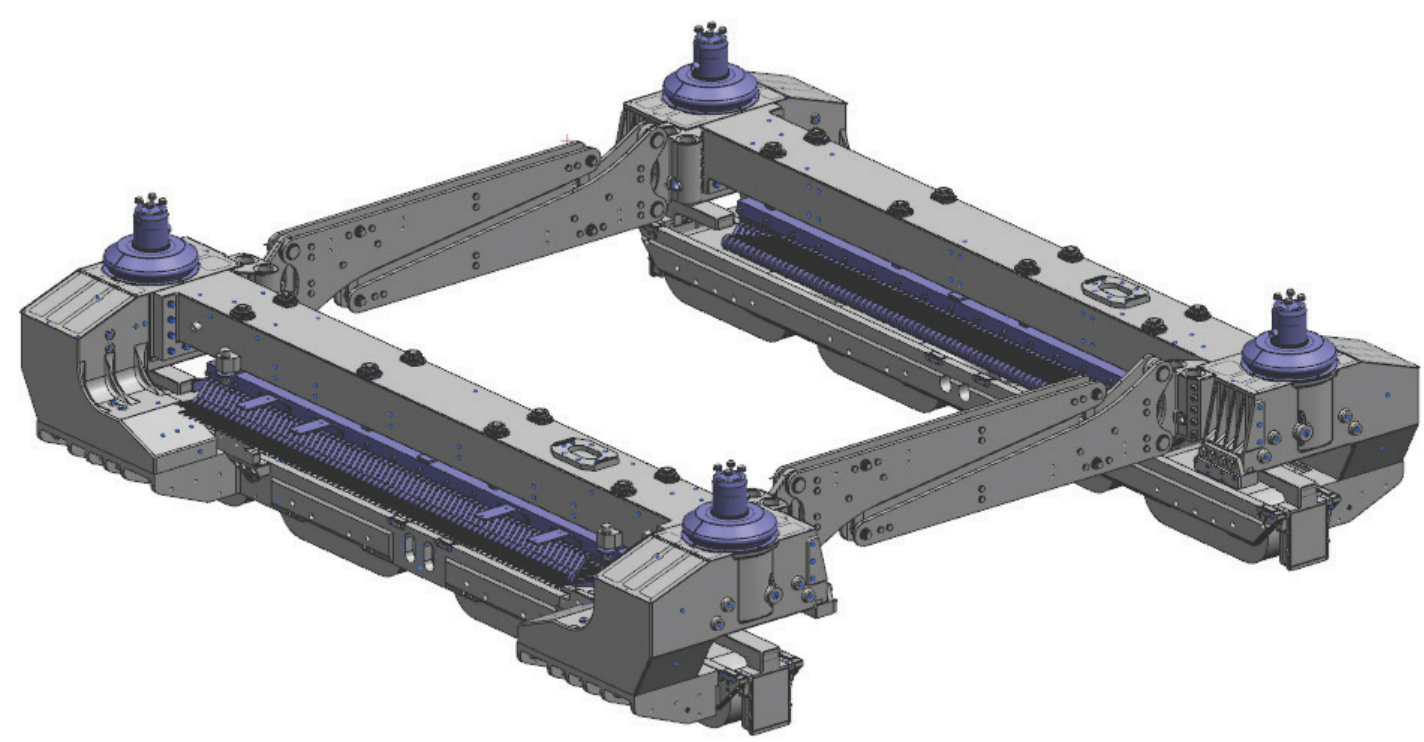

Fig. 9. The original suspension bogie applied in the Changsha Maglev Express

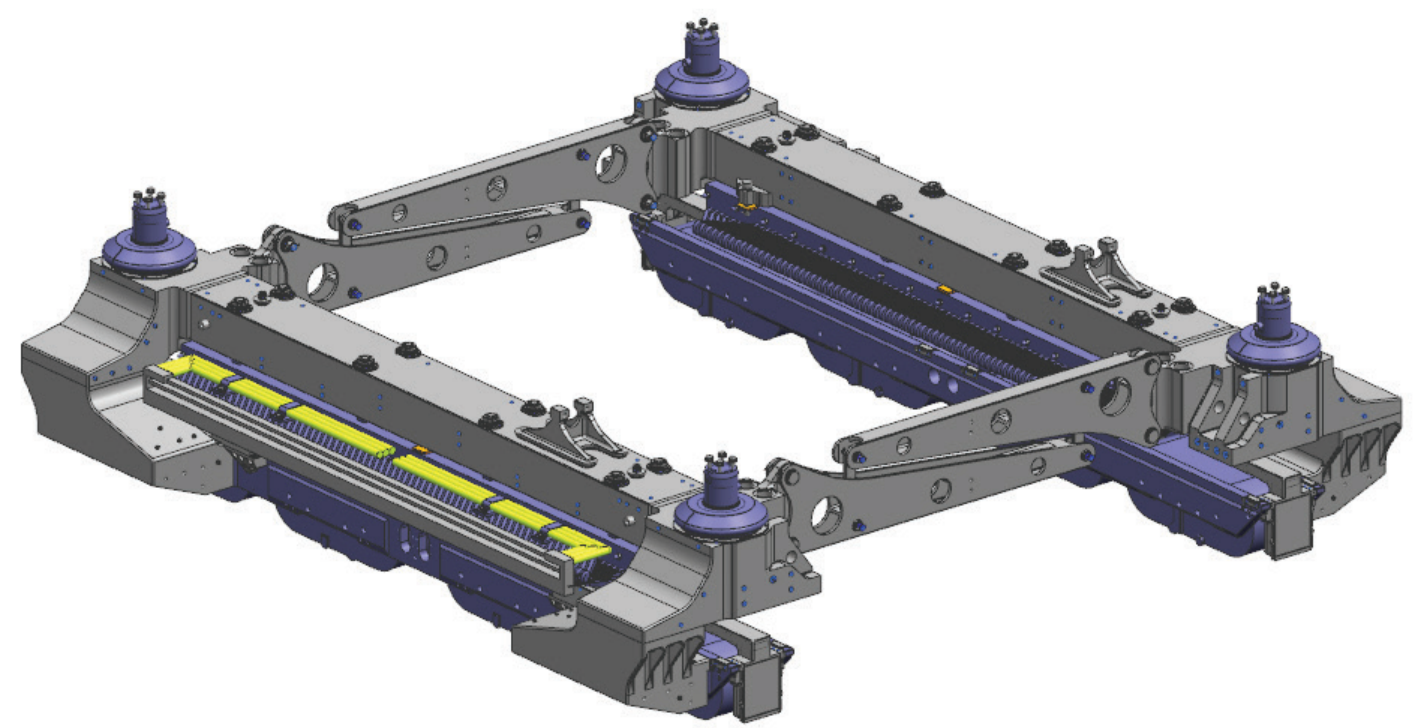

Fig. 10. The new designed suspension bogie for Fast-speed Maglev Train

\section{CONCLUSION}

The fast-speedmaglev train with three vehicles marshalling has been produced and tested on the Zhuzhoumedium-lowspeed maglev test line (Fig. 11) in the middle of 2018. The new designed LIMs' propulsion and suspension bogie dynamic performance weretotally verified, but due to the limitation that the length of test line is only $1.55 \mathrm{~km}$, the maximum running speed was $70 \mathrm{~km} / \mathrm{h}$. 


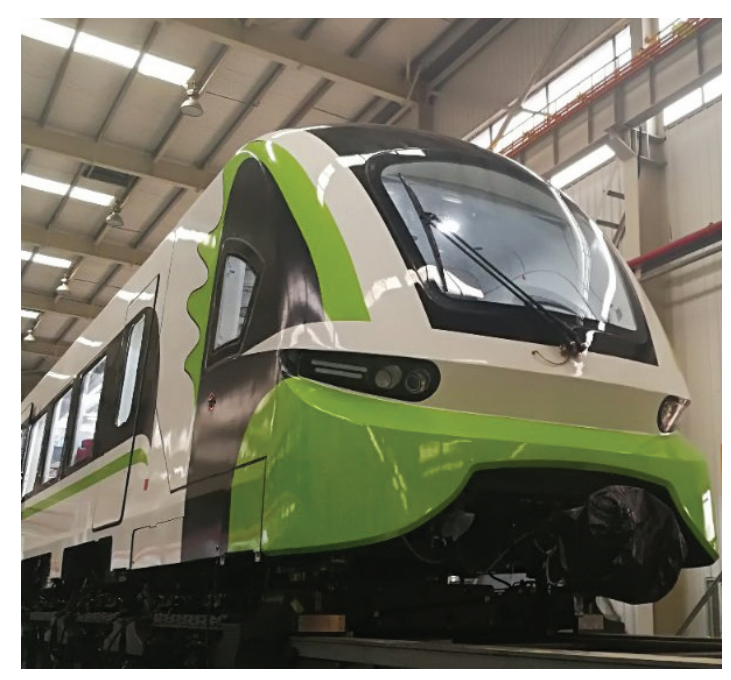

Fig. 11. Zhuzhou Fast-speed maglev train with three vehicles marshalling (in 2018)

\section{ACKNOWLEGEMENTS}

This paper is supported by the National key Research and Development Plan (No. 2016YFB1200601).

\section{References}

1. Liu YM, Yang Y. Linear motor driving metro vehicle - a new mode for urban mass transit. Electric locomotives \& mass transit vehicles. 2003;26(4):4-7. (in Chinese).

2. Fang Y, Li GG, Lv G. Linear motor and its application in urban rail transit.Urban Rapid rail transit. 2006;19(1):1-6. (in Chinese).

3. Yan LG. Development and application of the maglevtransportation system. IEEE Transactions on Applied Superconductivity. 2008;18(2):92-98. doi: 10.1109/tasc.2008.922239

4. Liu SK, Chang WS, YinLM. The running experiment description of Japan maglev train HSST-100. Electric drive for locomotive. 1997;6:29-31. (in Chinese).

5. Park SC, Lee WM, Kim KM. Analysis of linear inductionmotors for MAGLEV according to the secondary conductor structure. Proceedings of the International Conference on Electrical Machine and Systems; 2007; Seoul, Korea: IEEE; 2007.

6. Yang T, Zhou LB, Li LR. Finite element analysis of linear induction motor for transportation systems. Proceedings of the IEEE Vehicle Power and Propulsion Conference (VPPC 2008); 2008 Harbin, China: IEEE, 2008. doi: 10.1109/vppc.2008.4677591

\section{Information about the authors:}

Yang Ying, Master, Professor Level Senior Engineer;;

ORCID: 0000-0002-3125-2126;

E-mail: 2560828867@qq.com 
Deng Jiangming, Doctor, Senior engineer;

ORCID: 0000-0003-3450-2386;

E-mail: senmingt@163.com

Tong Laisheng, Ph.D, Professor Level Senior Engineer;

ORCID: 0000-0001-6905-5198;

E-mail: alanatlsh@126.com

Li Xiaochun, Master, Senior engineer;

ORCID: 0000-0001-6439-7711;

E-mail:6258755@qq.com

Peng Qibiao, Bachelor, Professor Level Senior Engineer;

ORCID: 0000-0003-0082-4221;

E-mail: pengqibi@sina.com

Zhang Wenhui, Master, Engineer;

ORCID: 0000-0003-1739-8724;

E-mail: 122784486@qq.com

\section{To cite this article:}

Yang Y, Deng J, Tong L, et al. Study on the Optimization of Linear Induction Motor Traction System for Fast-Speed Maglev Train. Transportation Systems and Technology. 2018;4(3 suppl. 1):156164. doi: 10.17816/transsyst201843s1156-164 